\title{
Determining the operational status of a three phase induction motor using a predictive data mining model
}

Aderibigbe Israel Adekitan, Adeyinka Adewale, Alashiri Olaitan

Department of Electrical and Information Engineering, Covenant University, Nigeria

\begin{tabular}{l} 
Article Info \\
\hline Article history: \\
Received Sep 18, 2018 \\
Revised Nov 20, 2018 \\
Accepted Nov 24, 2018 \\
\hline Keywords: \\
Machine learning \\
Motor performance \\
characteristics \\
Negative and positive sequence \\
component \\
Power quality \\
Three phase induction motor \\
Voltage unbalance
\end{tabular}

Keywords:

Machine learning

Motor performance

Negative and positive sequence

component

Three phase induction motor

oltage unbalance

\begin{abstract}
The operational performance of a three-phase induction motor is impaired by unbalanced voltage supply due to the generation of negative sequence currents, and negative sequence torque which increase motor losses and also trigger torque pulsations. In this study, data mining approach was applied in developing a predictive model using the historical, simulated operational data of a motor for classifying sample motor data under the appropriate type of voltage supply i.e. balanced (BV) and unbalance voltage supply (UB $=1 \%$ to $5 \%$ ). A dataset containing the values of a three-phase induction motor's performance parameter values was analysed using KNIME (Konstanz Information Miner) analytics platform. Three predictive models; the Naïve Bayes, Decision Tree and the Probabilistic Neural Network (PNN) Predictors were deployed for comparative analysis. The dataset was divided into two; $70 \%$ for model training and learning, and $30 \%$ for performance evaluation. The three predictors had accuracies of $98.649 \%, 100 \%$ and $98.649 \%$ respectively, and this confirms the suitability of data mining methods for predictive evaluation of a three-phase induction motor's performance using machine learning.
\end{abstract}

Copyright (C) 2019 Institute of Advanced Engineering and Science. All rights reserved.

\section{Corresponding Author:}

Aderibigbe Israel Adekitan,

Department of Electrical and Information Engineering,

Covenant University,

Ota, Ogun State, Nigeria.

Email: aderibigbe.adekitan@covenantuniversity.edu.ng

\section{INTRODUCTION}

Three phase induction motors (TPIM) have found applications in various commercial and industrial operations [1] due to its low cost, low maintenance requirement, rugged design and non-complex construction. The importance of a TPIM was also emphasized by [2] that proposed a drive system for converting single phase to three phase for powering induction motors in rural areas where only single phase supply is available. A three-phase induction motor is a poly-phase equipment which requires a three phase supply to run. Three phase supply systems are theoretically designed to have a balanced and equal voltage magnitude per phase, but due to operational realities such as unreliable power supply [3], line disturbances, motor winding factors, the ratio of three phase to single phase loads [4], transformer faults, line transposition issues, unequal transformer tap settings, heavy commercial loads and so forth; the voltage magnitude of each phase of a three phase supply are unequal sometimes, and the line to line phase shift may also deviate from the normal $120^{\circ}$. This abnormal supply condition is referred to as voltage unbalance [4], [5]. Voltage unbalance exists in most supply networks and it is quite severe in weak power systems [6].

The performance of a TPIM is impaired when operating under unbalance voltage conditions. Voltage unbalance stimulates increased motor losses which results in increased heat generation that may lead to early motor failure [7], [8]. Voltage unbalance reduces motor efficiency thereby increasing energy cost for the user [9], and by implication, the reduced efficiency increases the system load on the power plant which 
unnecessarily depletes the energy reserve of the power plant [10]. Voltage unbalance creates a magnetic flux that opposes the main flux, and this causes power and torque oscillation at twice the frequency of the supply. Consequently, the opposing flux leads to the generation of negative sequence currents that trigger increased motor losses [11], and heat production which may result in local hot spots in the stator windings [7], [12], [13].

Using Fortescue Theorem an unbalance voltage can be resolved into three symmetrical sequence components, these are - the zero sequence, the positive sequence and the negative sequence components [14]. Given line voltages $V_{a}, V_{b}$ and $V_{c}$, these can be transformed into sequence components as shown in Figure 1.

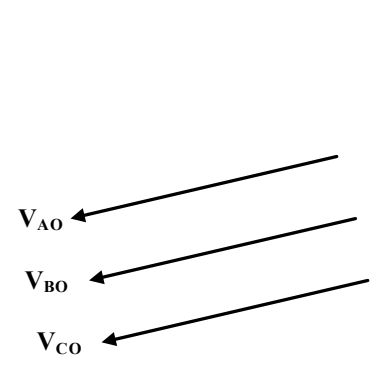

(a)

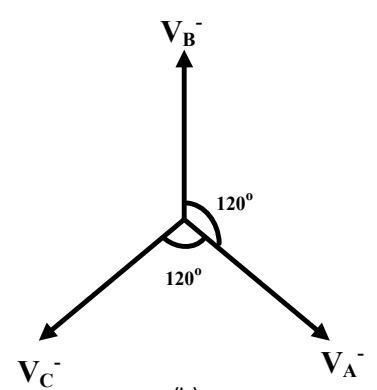

(b)

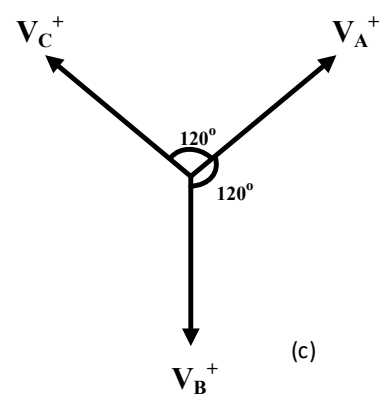

Figure 1. (a) Zero sequence (b) Positive sequence and (c) Negative sequence voltage components

By design, an induction motor can tolerate reasonable levels of voltage unbalance but when the unbalance becomes excessive the motor must be derated to prevent early damage due to voltage-unbalance induced harmonic currents [7]. In the study by [15], a Neural Network controller was proposed for reducing torque ripple and current harmonics. The derating factor of an induction motor is determined by analysing comparatively the performance of the motor under unbalanced and balanced voltage operational conditions, and it is calculated as the ratio of the mechanical output power during unbalance voltage to that under balanced supply [16], [17]. Power supply quality is a major induction motor performance determinant [18][20], and as such, adequate effort must be put in place to manage power quality issues by using modern techniques [21] to guarantee quality power supply in order to ensure motor reliability and optimal performance.

When an induction motor is operating either under balanced or unbalanced voltage conditions, the performance measurement parameters of the motor such as the rotor and stator currents, the negative and positive sequence torque, the electromagnetic power, the air gap power, the rotor and the stator copper winding losses, the real and reactive input power, the power factor etc. changes accordingly with the voltage supply conditions. In this study, the simulated operational data of a three-phase induction motor operating within the motoring slip range $(0<\operatorname{slip}<1)$ under balanced $(\mathrm{BV})$ and unbalance voltage supply $(\mathrm{UB}=1 \%$ to $5 \%)$ is collected and processed for predictive modelling using data mining. A predictive model was developed using KNIME (Konstanz Information Miner) Analytics Platform to analyse the dataset toward developing a functional model that can determine the nature of the voltage supply whether balanced or not using the motor's performance historical data.

\section{NATIONAL ELECTRICAL MANUFACTURES ASSOCIATION (NEMA)}

The dataset deployed in this study was generated using NEMA MG1 (1993) definition of voltage unbalance. According to NEMA, voltage unbalance is defined as:

$$
\begin{aligned}
& \text { Voltage unbalance }=\frac{\text { max. deviation from average line voltage }}{\text { average line voltage magnitude }} \times 100 \% \\
& =\frac{\operatorname{Max}\left[\left|\mathrm{V}_{\mathrm{ab}}-\mathrm{V}_{\mathrm{Lavg}}\right|,\left|\mathrm{V}_{\mathrm{bc}}-\mathrm{V}_{\text {Lavg }}\right|,\left|\mathrm{V}_{\mathrm{ca}}-\mathrm{V}_{\text {Lavg }}\right|\right]}{\mathrm{V}_{\text {Lavg }}} \times 100 \%
\end{aligned}
$$


Where $\mathrm{V}_{\mathrm{Lavg}}=\frac{\left(\mathrm{V}_{\mathrm{ab}}+\mathrm{V}_{\mathrm{bc}}+\mathrm{V}_{\mathrm{ca}}\right)}{3}$

The operational motor performance dataset depicts a $415 \mathrm{~V}$ three phase induction motor having the following per unit parameters $\mathrm{Xm}=2.41 \Omega, \mathrm{Xs}=0.12 \Omega, \mathrm{Xr}=0.12 \Omega, \mathrm{Rr}=0.084 \Omega, \mathrm{Rs}=0.073 \Omega$ with a base impedance of 3.304. The voltage variations considererd are the balanced voltage (BV), $1 \%$ unbalance (1\%UB), $2 \%$ unbalance $(2 \% \mathrm{UB}), 3 \%$ unbalance $(3 \% \mathrm{UB}), 4 \%$ unbalance $(\% \mathrm{UB})$, and $5 \%$ unbalance $(5 \% \mathrm{UB})$ supply conditions, in line with NEMA recommendation of $5 \%$ maximum unbalance. The per phase equivalent circuit diagram of a typical TPIM is presented in Figure 2.

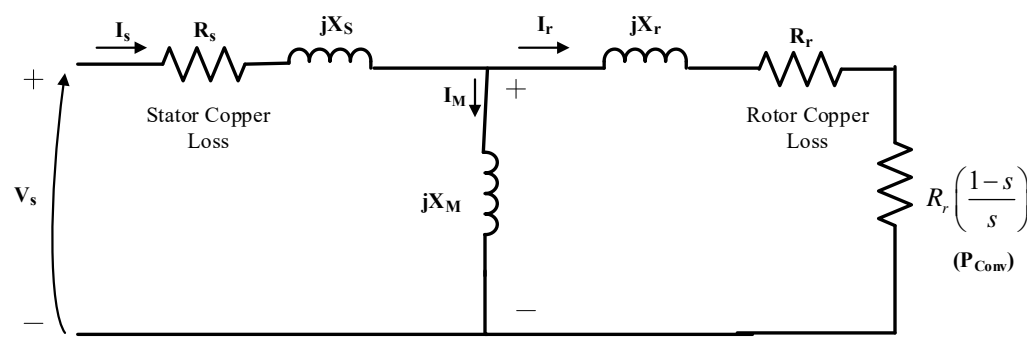

Figure 2. Per phase equivalent diagram of a TPIM

\section{RESEARCH METHOD}

Data mining is a field of study that encompasses both statistics and machine learning, and it is a subfield of computer science that enables intelligent extraction of useful information [22, 23], patterns and knowledge [24] from dataset towards creating models that represent the knowledge acquired from the dataset thereby making such knowledge reusable for making decisions on similar cases. The KNIME Analytics Platform was deployed to achieve the motor supply-status predictive modelling. KNIME is the open source software with capacity to handle large volume of data; equipped with extensive tools and resources. KNIME has found application in various aspects of data mining projects handled by more than 6000 professionals globally [25], [26].

KNIME is the modular data integration and processing platform that enables users to visually create data flows for data analysis and exploration [27]. In the study by [26], a model for predicting the internal faults of an oil-immersed power transformer using historical fault data was developed using KNIME. The model developed using probabilistic neural network achieved an accuracy of $80 \%$. Data processing and analysis is significant in developing a data mining workflow, the motor parameters for the six voltage supply scenarios were appropriately sorted and prepared for supervised learning using KNIME workflow.

\section{DATA BASED PREDICTIVE MODELLING OF THREE PHASE INDUCTION MOTOR VOLTAGE STATUS USING KNIME}

In the study [28], an Artificial Neutral Network (ANN) model was trained to detect voltage unbalance in the motor's operational dataset using the historical voltage dataset as a target for training the feed-forward network ANN model. The accuracy of the ANN model was assessed using the mean square error. The use of ANN and adaptive neuro-fuzzy inference system for predicting the parameters of an induction motor was proposed [29]. Also, an online fault detection and performance evaluation simulation was developed [30] using the phase currents, the voltage and the motor speed for assessment. Likewise, the feasibility of using naive bayes data mining algorithm for identification and classification of motor bearing faults was demonstrated [31], while in the study [32] fuzzy logic was applied for identifying short and open circuit TPIM faults.

In this study, a KNIME workflow shown in Figure 3 was developed for data mining the operational motor performance dataset toward enabling a prediction of the nature of the voltage supply i.e. whether balanced or unbalanced. For comparative analysis, three predictive algorithms were applied, and these are Probabilistic Neural Network (PNN), Naïve Bayes Predictor and Decision Tree Predictor. The motor operational dataset contains the motor slip, the negative and positive sequence current and torque, the rotor and stator current per phase, the total rotor and stator resistive copper losses, the real, reactive and apparent input power, the air gap power and the electromechanical power. The voltage supply status for each sample

Determining the operational status of a three phase induction motor using ... (Aderibigbe Israel Adekitan) 
case was classified as $\mathrm{BV}, 1 \% \mathrm{UB}, 2 \% \mathrm{UB}, 3 \% \mathrm{UB}, 4 \% \mathrm{UB}$, and $5 \% \mathrm{UB}$ in the dataset. 246 data samples for each of the parameters was shared in the ratio $7: 3$ using stratified sampling; $70 \%$ for training and $30 \%$ for predictive evaluation.

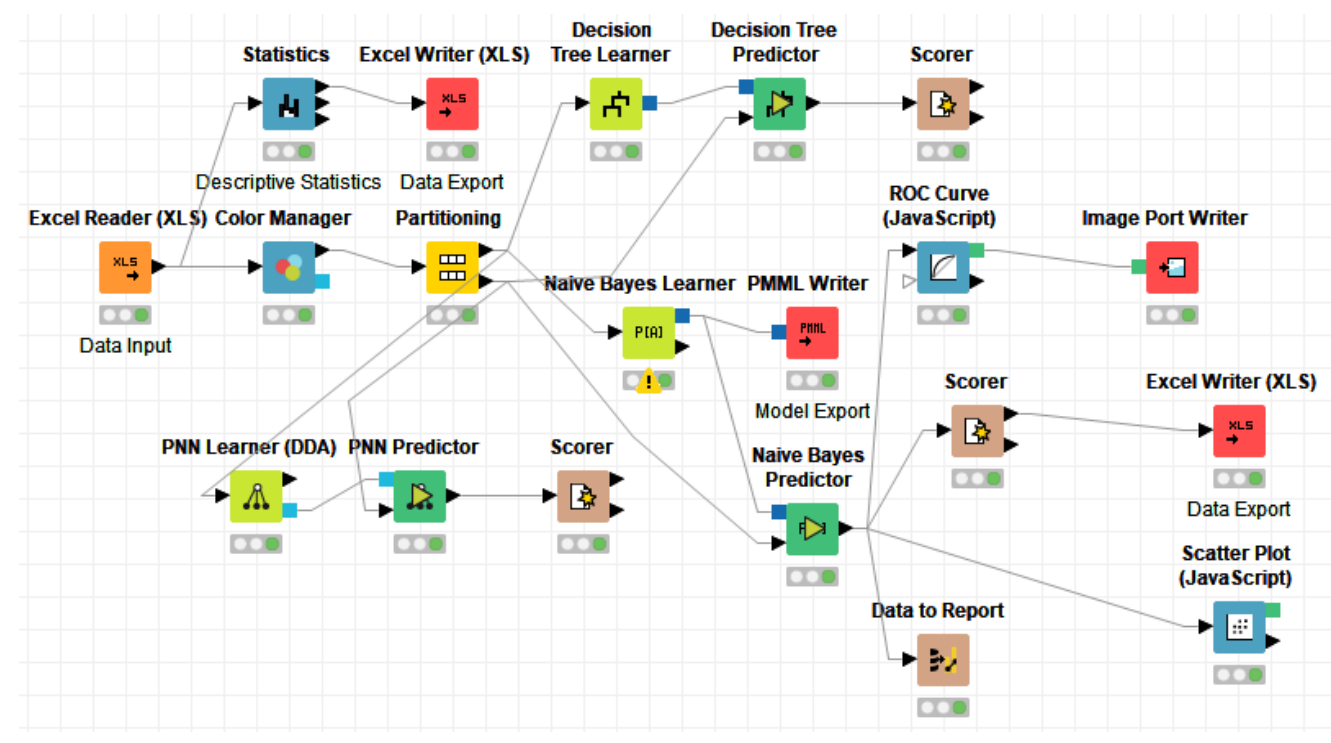

Figure 3. Supply voltage status predictive KNIME workflow

\section{RESULTS AND DISCUSSION}

The descriptive statistics of the values of the motor parameters are presented in Table 1. The data mining workflow implemented, developed various statistical properties for each of the parameters and using the uniqueness of each, a representative model was automatically computed which depicts the relationship between the voltage status and the motor parameters.

Table 1. Descriptive Statistics of the Motor Parameter

\begin{tabular}{|c|c|c|c|c|c|c|c|}
\hline & Min & Max & Mean & Std. deviation & Variance & Skewness & Kurtosis \\
\hline Slip & 0 & 1 & 0.5 & 0.2964 & 0.0879 & 0 & -1.2014 \\
\hline Iseqpos (A) & 35.0894 & 259.10 & 195.95 & 63.17 & 3990.38 & -1.09 & 0.08 \\
\hline Iseqneg (A) & 0 & 8.06 & 3.92 & 2.68 & 7.20 & 0.00 & -1.26 \\
\hline $\operatorname{Ira}(\mathrm{A})$ & 20.1059 & 246.78 & 186.64 & 61.28 & 3755.21 & -1.15 & 0.29 \\
\hline $\operatorname{Irb}(\mathrm{A})$ & 20.1059 & 252.87 & 187.57 & 63.07 & 3977.90 & -1.14 & 0.25 \\
\hline $\operatorname{Irc}(\mathrm{A})$ & 14.1331 & 246.68 & 181.77 & 62.35 & 3887.90 & -1.13 & 0.24 \\
\hline Isa (A) & 35.0894 & 259.21 & 197.04 & 62.58 & 3916.74 & -1.10 & 0.13 \\
\hline Isb (A) & 35.0894 & 265.61 & 198.69 & 63.53 & 4036.38 & -1.07 & 0.05 \\
\hline Isc (A) & 27.708 & 259.10 & 192.23 & 63.41 & 4020.59 & -1.08 & 0.07 \\
\hline Pr - Total (W) & 336.5783 & 50706.82 & 31813.92 & 15866.79 & 251754986.50 & -0.62 & -0.95 \\
\hline Ps -Total (W) & 890.9139 & 48617.81 & 30675.13 & 15047.41 & 226424640.37 & -0.61 & -0.95 \\
\hline Pin $(\mathrm{W})$ & 14354.0474 & 106461.27 & 92125.81 & 22812.30 & 520400920.13 & -2.07 & 3.35 \\
\hline Pin (VAR) & 20739.4616 & 157732.27 & 104919.53 & 43619.64 & 1902672799.81 & -0.58 & -1.01 \\
\hline Pin (VA) & 25222.2906 & 186399.71 & 140907.65 & 45407.87 & 2061874313.23 & -1.09 & 0.08 \\
\hline Airgap Power & 13463.1335 & 75872.50 & 61450.68 & 13577.87 & 184358466.84 & -1.56 & 2.89 \\
\hline Elect Mech Power & 0 & 54920.08 & 29636.76 & 17886.50 & 319926709.18 & -0.08 & -1.37 \\
\hline Pos Seq T (Nm) & 85.709 & 482.84 & 392.89 & 86.83 & 7539.95 & -1.63 & 3.05 \\
\hline Neg Seq T (Nm) & -0.2643 & 0.00 & -0.07 & 0.07 & 0.01 & -0.82 & -0.48 \\
\hline $\mathrm{pf}$ & 0.5329 & 0.86 & 0.68 & 0.11 & 0.01 & 0.28 & -1.32 \\
\hline
\end{tabular}

The statistical variations of the motor's rotor, stator and sequence currents in ampere for all the voltage supply modes, both balanced and unbalanced are shown in Figure 4. The box plots reveal the minimum, the lower quartile, the median, the upper quartile and the maximum values for each of the current parameters. In Figure 5, the real (W), reactive (VAR), apparent (VA), air gap (W) and electromagnetic power (W) of the motor is displayed as a box plot.

Int J Pow Elec \& Dri Syst, Vol. 10, No. 1, March 2019: 93 - 103 


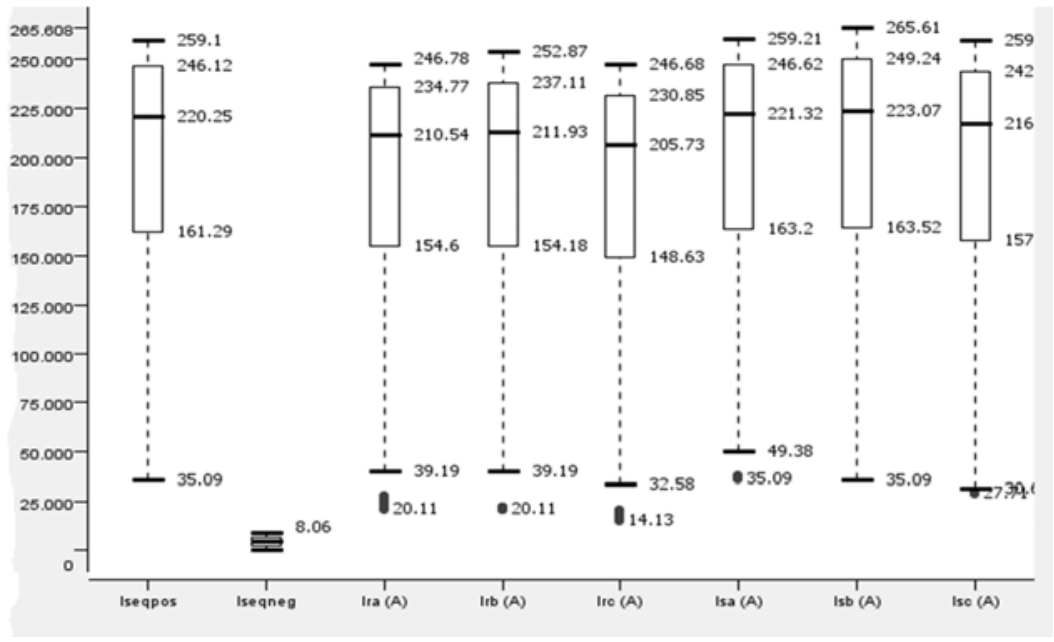

Figure 4. A box plot showing the magnitude spread of the motor currents

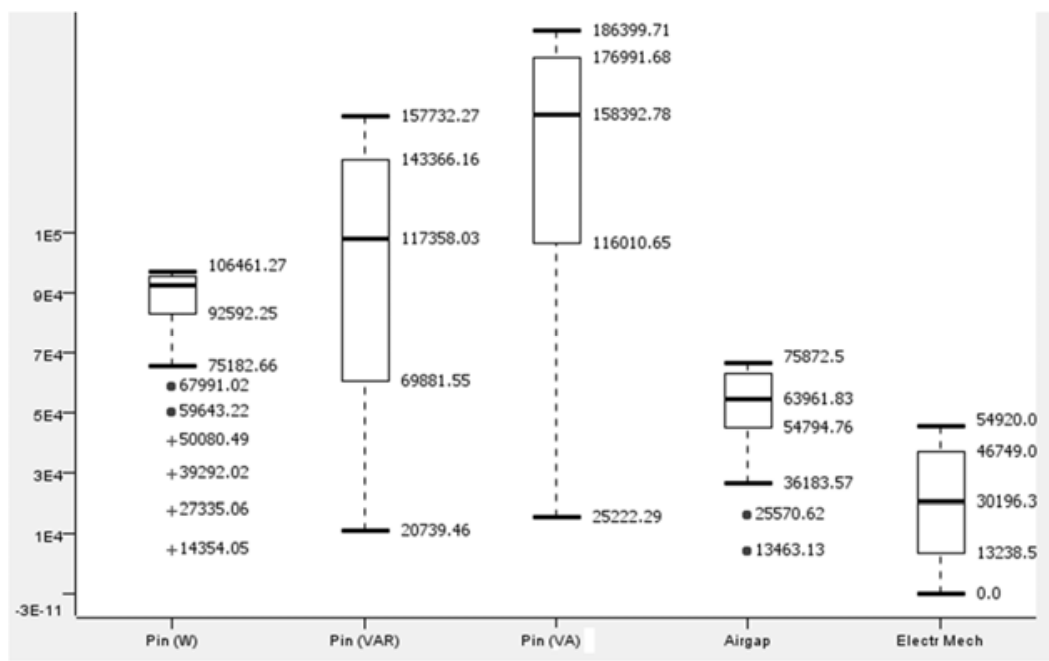

Figure 5. A box plot showing the magnitude spread of the motor's power components

In Figure 6, the statistical spread of the values of the rotor copper losses and the stator copper losses in watt is presented as a box plot. The rotor losses increased from $336.58 \mathrm{~W}$ to $50706.82 \mathrm{~W}$ with increasing slip and voltage unbalance, while the total stator winding copper losses increased from $890.91 \mathrm{~W}$ to $48617.81 \mathrm{~W}$. Figure 7 presents the variation in the magnitude of the positive and negative sequence torque in $\mathrm{Nm}$.

The variation of the negative sequence torque in $\mathrm{Nm}$ for the $\mathrm{BV}, 1 \% \mathrm{UB}, 2 \% \mathrm{UB}, 3 \% \mathrm{UB}, 4 \% \mathrm{UB}$ and $5 \% \mathrm{UB}$ voltage conditions is displayed in Figure 8 . The box plot reveals that at 5\%UB there is a significant increase in the magnitude of the negative sequence torque as compared with the value when the voltage was balanced. Similarly, Figure 9 presents a box plot of the sequence current (A) for the BV, $1 \%$ UB, 2\%UB, $3 \% \mathrm{UB}, 4 \% \mathrm{UB}$ and $5 \% \mathrm{UB}$ voltage conditions. The sequence current has the maximum value at $5 \%$ voltage unbalance condition.

The changes in the rotor winding copper losses for the BV, $1 \% \mathrm{UB}, 2 \% \mathrm{UB}, 3 \% \mathrm{UB}, 4 \% \mathrm{UB}$ and $5 \% \mathrm{UB}$ voltage conditions is displayed in the box plot of Figure 10. Figure 11 details the variations in the stator winding copper losses for the balanced voltage (BV) and the unbalanced $(1 \% \mathrm{UB}$ to $5 \% \mathrm{UB})$ voltage conditions. 


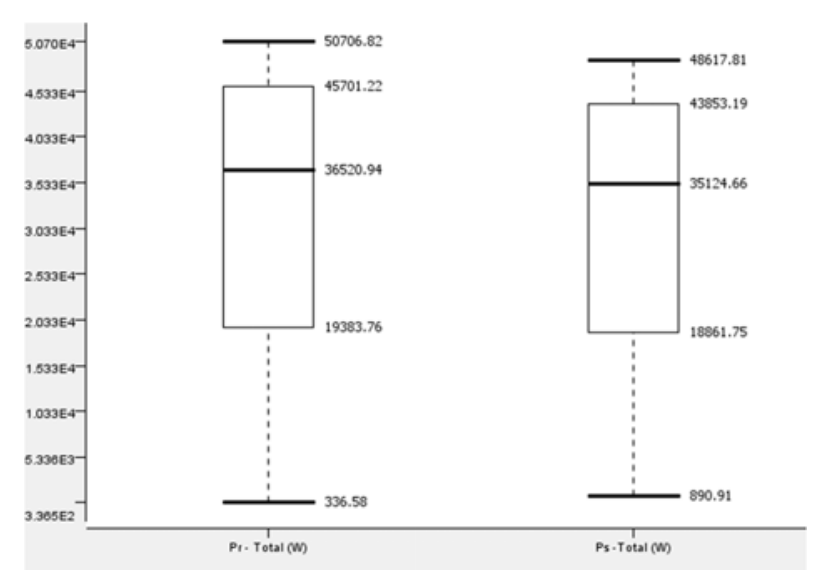

Figure 6. A box plot of the rotor and stator winding copper losses

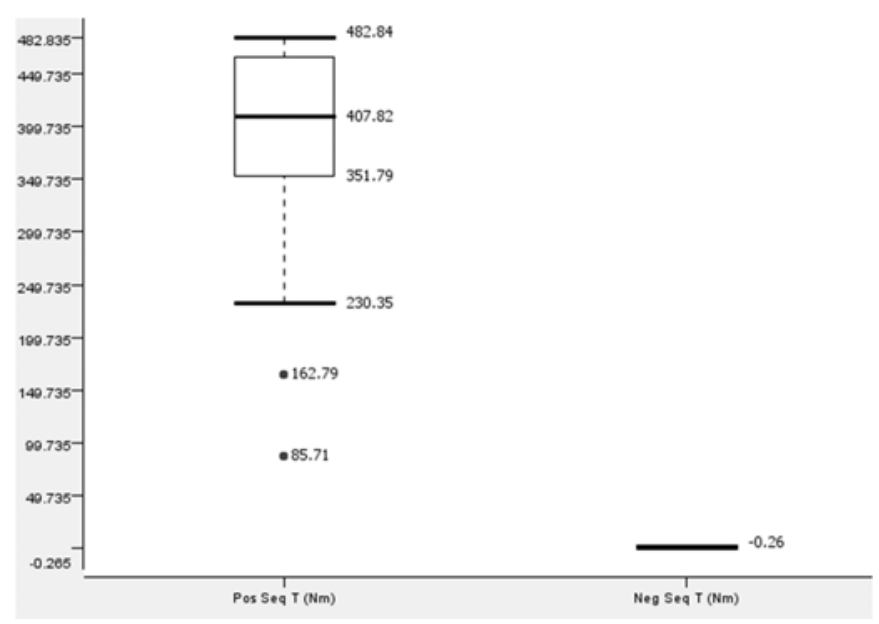

Figure 7. A box plot showing the magnitude spread of the positive and negative sequence torque

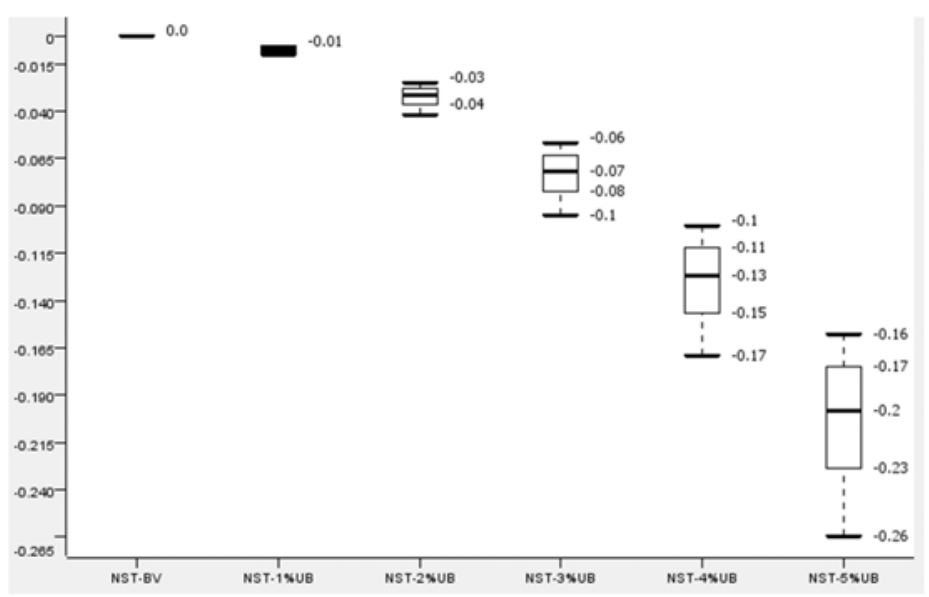

Figure 8 . A box plot showing the negative sequence torque in $\mathrm{Nm}$ from balanced to $5 \%$ unbalanced voltage 


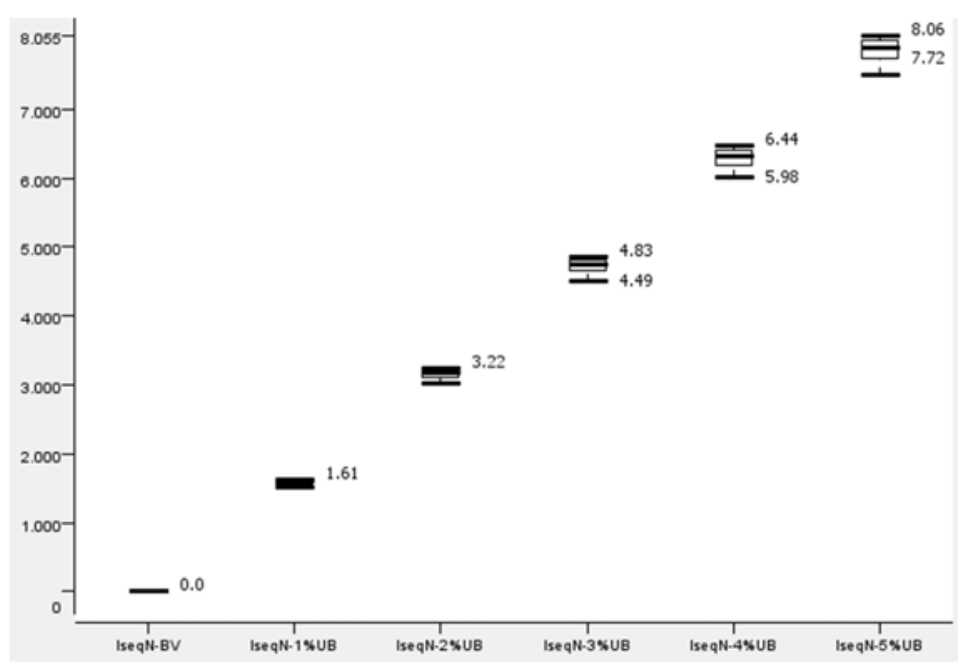

Figure 9. A box plot showing the negative sequence current in $\mathrm{Nm}$ for balanced to $5 \%$ unbalanced voltage

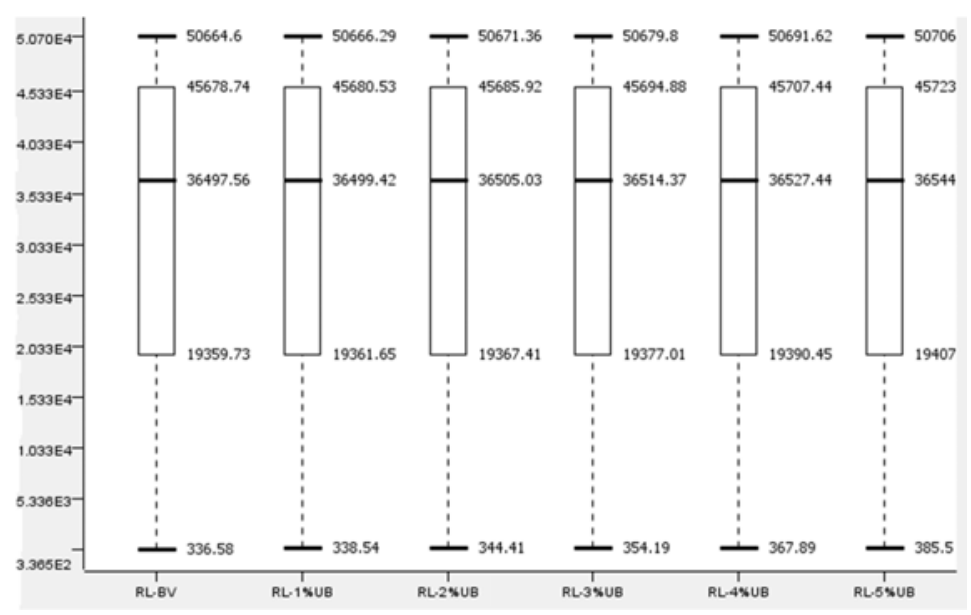

Figure 10. A box plot of the rotor copper losses with increasing unbalance voltage

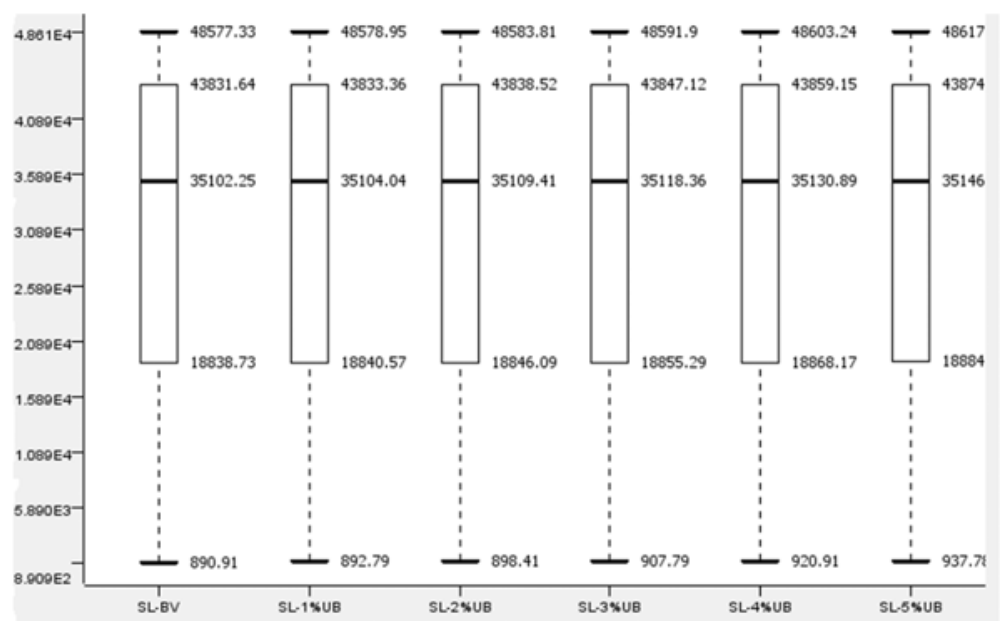

Figure 11. A box plot of the stator copper losses with increasing unbalance voltage 


\subsection{The naïve bayes predictor results}

Using the Naïve Bayes predictor an accuracy of $98.649 \%$ was achieved. The scatter plot of the classified samples as shown in Figure 12. The confusion matrix of the Naïve Bayes predictor is presented in Table 2. Out of the total 73 samples randomly selected for performance evaluation, only one sample was misclassified. Figure 13 shows the ROC curve for the $100 \%$ correctly predicted BV samples while Figure 14 presents the RC curve for the $2 \%$ unbalance voltage prediction which has $94.2 \%$ accuracy due to the misclassification of a sample.

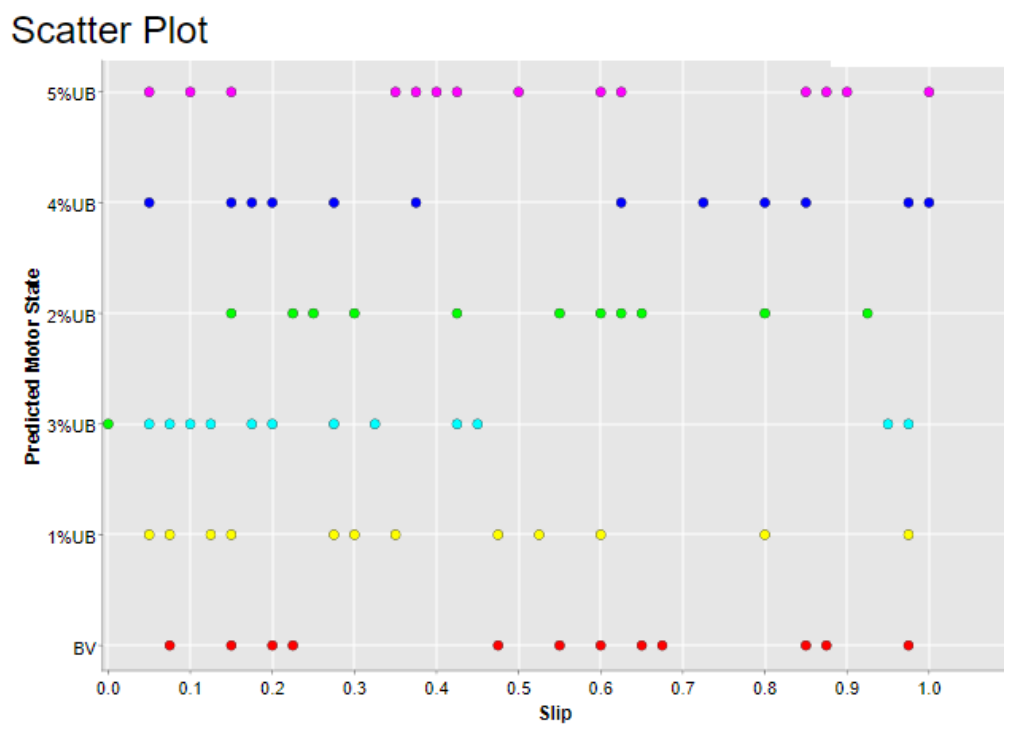

Figure 12. Scatter plot of the classified samples

Table 2. Confusion Matrix of the Naïve Bayes Predictor

\begin{tabular}{ccccccc}
\hline & $\mathrm{BV}$ & $1 \% \mathrm{UB}$ & $2 \% \mathrm{UB}$ & $3 \% \mathrm{UB}$ & $4 \% \mathrm{UB}$ & $5 \% \mathrm{UB}$ \\
\hline $\mathrm{BV}$ & 12 & 0 & 0 & 0 & 0 & 0 \\
$1 \% \mathrm{UB}$ & 0 & 12 & 0 & 0 & 0 & 0 \\
$2 \% \mathrm{UB}$ & 0 & 0 & 11 & 1 & 0 & 0 \\
$3 \% \mathrm{UB}$ & 0 & 0 & 0 & 12 & 0 & 0 \\
$4 \% \mathrm{UB}$ & 0 & 0 & 0 & 0 & 12 & 0 \\
$5 \% \mathrm{UB}$ & 0 & 0 & 0 & 0 & 0 & 14 \\
\hline
\end{tabular}

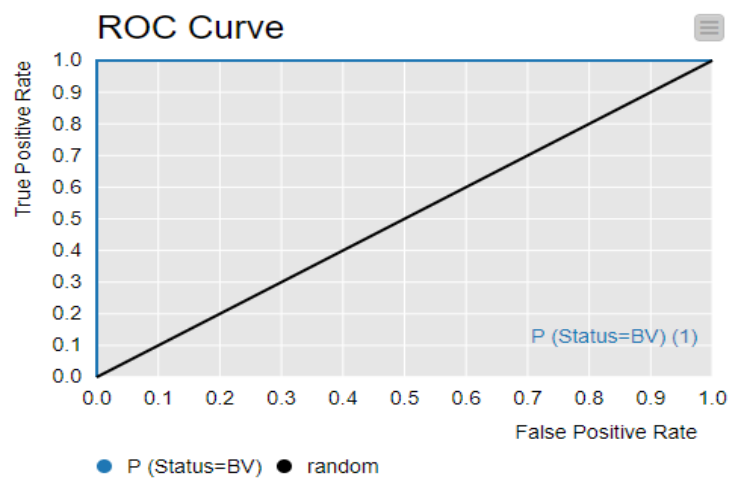

Figure 13. ROC curve showing the accuracy of the balanced voltage sample classifications

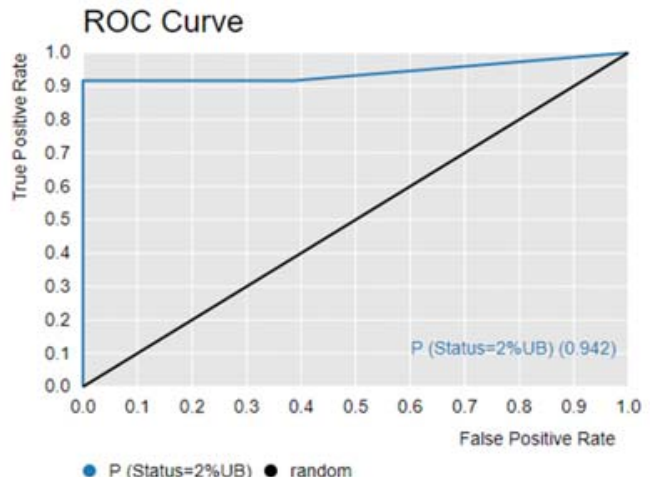

Figure 14. ROC curve showing the accuracy of the 2\%UB sample classifications 


\subsection{The decision tree predictor results}

The confusion matrix of the Decision Tree predictor is presented in Table 3. All the 74 samples randomly selected for performance evaluation were accurately classified as shown by the diagonal elements of Table 3.

Table 3. Confusion matrix of the decision tree predictor

\begin{tabular}{ccccccc}
\hline & $\mathrm{BV}$ & $1 \% \mathrm{UB}$ & $2 \% \mathrm{UB}$ & $3 \% \mathrm{UB}$ & $4 \% \mathrm{UB}$ & $5 \% \mathrm{UB}$ \\
\hline BV & 12 & 0 & 0 & 0 & 0 & 0 \\
$1 \% \mathrm{UB}$ & 0 & 12 & 0 & 0 & 0 & 0 \\
$2 \% \mathrm{UB}$ & 0 & 0 & 12 & 0 & 0 & 0 \\
$3 \% \mathrm{UB}$ & 0 & 0 & 0 & 12 & 0 & 0 \\
$4 \% \mathrm{UB}$ & 0 & 0 & 0 & 0 & 12 & 0 \\
$5 \% \mathrm{UB}$ & 0 & 0 & 0 & 0 & 0 & 14 \\
\hline
\end{tabular}

\subsection{The PNN predictor results}

Voltage supply status prediction using trained Probabilistic Neural Network node was also performed, the confusion matrix of the PNN predictor is presented in Table 4. Of all the 73 samples randomly selected only one was misclassified.

Table 4. Confusion matrix of the PNN predictor

\begin{tabular}{ccccccc}
\hline & $\mathrm{BV}$ & $1 \% \mathrm{UB}$ & $2 \% \mathrm{UB}$ & $3 \% \mathrm{UB}$ & $4 \% \mathrm{UB}$ & $5 \% \mathrm{UB}$ \\
\hline $\mathrm{BV}$ & 12 & 0 & 0 & 0 & 0 & 0 \\
$1 \% \mathrm{UB}$ & 0 & 12 & 0 & 0 & 0 & 0 \\
$2 \% \mathrm{UB}$ & 0 & 0 & 12 & 0 & 0 & 0 \\
$3 \% \mathrm{UB}$ & 0 & 0 & 0 & 12 & 0 & 0 \\
$4 \% \mathrm{UB}$ & 0 & 0 & 0 & 0 & 11 & 1 \\
$5 \% \mathrm{UB}$ & 0 & 0 & 0 & 0 & 0 & 14 \\
\hline
\end{tabular}

\subsection{Summary of model predictions}

The comparative performance of the three predictors is presented in Table 5. The decision tree predictor had the highest performance with accuracy of $100 \%$ for the $\mathrm{BV}, 1 \% \mathrm{UB}, 2 \% \mathrm{UB}, 3 \% \mathrm{UB}, 4 \% \mathrm{UB}$ and $5 \%$ UB voltage samples considered. The accuracy of the model is significantly high because a lot of motor operational parameters were considered in the model. All the simulated parameters may not be readily available or easy to measure in practical studies, and as such, the expected accuracy for experimentally generated dataset will be quite lower.

Table 5. Comparison of the performance of the three data mining predictors

\begin{tabular}{cccc}
\hline & Naïve Bayes & Decision Tree & PNN Predictor \\
\hline Correct Classified & 73 & 74 & 73 \\
Accuracy & $98.649 \%$ & $100 \%$ & $98.649 \%$ \\
Cohen's Kappa (k) & 0.984 & 1 & 0.984 \\
Wrong Classified & 1 & 0 & 1 \\
Error & $1.351 \%$ & $0 \%$ & $1.351 \%$ \\
\hline
\end{tabular}

\section{CONCLUSION}

In this study, data mining was applied to acquire knowledge from the dataset generated from the simulated operation of a three phase induction motor under balanced and unbalanced voltage supply. A predictive KNIME model was developed and three data mining algorithms; the Naïve Bayes, Decision Tree and PNN Predictor were trained using $70 \%$ of the total samples which were randomly selected. The knowledge acquired from the training was applied in predicting the type of supply that produced the remaining $30 \%$ of the motor operational data samples. The three predictors had accuracies of $98.649 \%, 100 \%$ and $98.649 \%$ respectively which indicates that the model was adequately able to acquire sufficient knowledge from the operational motor dataset, and this enabled the correct prediction of the type of voltage supply classified as balanced (BV), and unbalanced (1\%UB, 2\%UB, 3\%UB, 4\%UB and 5\%UB) voltage supply. The model developed was exported using the PMML writer and this creates an opportunity for reuse even on other platforms. The predictive accuracy achieved in this work is indicative of the suitability of data mining approach for motor performance monitoring. This study opens up further research opportunities for

Determining the operational status of a three phase induction motor using ... (Aderibigbe Israel Adekitan) 
deploying similar data mining models on practical motors for voltage quality monitoring using real time motor operational data.

\section{ACKNOWLEDGEMENTS}

The publication of this paper was sponsored by Covenant University Centre for Research, Innovation and Discovery.

\section{REFERENCES}

[1] K. Vinoth Kumar, S. Suresh Kumar, and A. Immanuel Selvakumar, "A review of voltage and current signature diagnosis in industrial drives," International Journal of Power Electronics and Drive Systems (IJPEDS), vol. 1, pp. 75-82, 2011.

[2] Z. M. S. El-Barbary, "Single-to-three phase induction motor sensorless drive system," Alexandria Engineering Journal, vol. 51, pp. 77-83, 2012.

[3] O. Olatunji, S. Akinlabi, A. Oluseyi, A. Abioye, F. Ishola, M. Peter, et al., "Electric Power Crisis in Nigeria: A Strategic Call for Change of Focus to Renewable Sources," in 2nd International Conference on Engineering for Sustainable World (ICESW 2018), 2018.

[4] A. Adekitan, A. Ogunjuyigbe, R. Ayodele, and I. Samuel, "The performance of a 3-Phase Induction Machine under Unbalance Voltage Regime," Journal of Engineering Science and Technology Review, vol. 10, pp. 136-143, 2017.

[5] P. Pillay and M. Manyage, "Definitions of voltage unbalance," IEEE Power Engineering Review, vol. 21, pp. 50-51, 2001.

[6] J. Faiz and H. Ebrahimpour, "Precise derating of three-phase induction motors with unbalanced voltages," in Fourtieth IAS Annual Meeting. Conference Record of the 2005 Industry Applications Conference, vol. 1, pp. 485-491, 2005.

[7] P. Gnacinski, "Effect of unbalanced voltage on windings temperature, operational life and load carrying capacity of induction machine," Energy Conversion and Management, vol. 49, pp. 761-770, 2008.

[8] B. N. Gafford, W. C. Duesterhoeft, and C. C. Mosher, "Heating of Induction Motors on Unbalanced," Power Apparatus and Systems, Part III. Transactions of the American Institute of Electrical Engineers, vol. 78, pp. 282-286, 1959.

[9] A. I. Adekitan, B. Adetokun, T. Shomefun, and A. Aligbe, "Cost implication of Line Voltage variation on Three Phase Induction Motor operation," TELKOMNIKA (Telecommunication Computing Electronics and Control), vol. 16, pp. 1404-1412, 2018.

[10] J. Faiz, E. H., and P. Pillay, "Influence of Unbalanced Voltage on the Steady-State Performance of a Three-Phase Squirrel-Cage Induction Motor," IEEE Transactions on Energy Conversion, vol. 19, pp. pp.657-62, 2004.

[11] C.-Y. Lee, B.-K. Chen, W.-J. Lee, and Y.-F. Hsu, "Effects of various unbalanced voltages on the operation performance of an induction motor under the same voltage unbalance factor condition," Electric Power Systems Research, vol. 47, pp. 153-163, 1998.

[12] P. Pillay, P. Hofmann, and M. Manyage, "Derating of induction motors operating with a combination of unbalanced voltages and over or undervoltages," IEEE Trans. Energy Conservation, vol. 17, pp. 485 - 491, 2002.

[13] Ebadi, S. Ali, Mirzaie, M. Zareinejad, and S. Asghar Gholamian, Torque analysis of three-phase induction motor under voltage unbalance using 2D FEM, International Journal of Engineering Science and Technology (IJEST), vol. 3, pp. 871-876, 2011.

[14] C. L. Fortescue, "Method of symmetrical coordinates applied to the solution of polyphase networks," AIEE Trans, vol. 37, pp. 1027-140, 1918.

[15] A. Sivakumar and N. B. Muthu Selvan, "Reduction of source current harmonics in ANN controlled induction motor," Alexandria Engineering Journal, vol. 57, pp. 1489-1499, September 2018.

[16] W. H. Kersting and W. H. Phillips, "Phase Frame Analysis of the Effects of Voltage Unbalance on Induction Machines," IEEE Transactions on Industry Applications, vol. 32, pp. pp.415-20, 1997.

[17] J. Faiz and H. Ebrahimpour, "Precise derating of three phase induction motors with unbalanced voltages," Energy Conversion and Management, vol. 48, pp. 2579-2586, 2007.

[18] A. I. Adekitan, "Supply instability induced torque variations of a three phase asynchronous motor," International Journal of Mechanical Engineering and Technology, vol. 9, pp. 572-583, 2018.

[19] P. Amaize, K. O. Ignatius, E. S. Oluwasogo, A. S. Alayande, and A. E. Airoboman, "Influence of Power Quality Problem on the Performance of an Induction Motor," American Journal of Electrical Power and Energy Systems, vol. 4, pp. 39-44, 2017.

[20] S. Shahbudin, Z. F. Mohmad, S. I. Suliman, M. Kassim, and R. Mohamad, "Classification of power quality disturbances at transmission system using support vector machines," Indonesian Journal of Electrical Engineering and Computer Science (IJEECS), vol. 6, pp. 310-317, 2017.

[21] S. Suraya, P. S. Sujatha, and B. Kumar, "A Novel Control Strategy for Compensation of Voltage Quality Problem in AC Drives," International Journal of Power Electronics and Drive Systems (IJPEDS), vol. 9, pp. 8-16, 2018.

[22] R. Myung, H. Yu, and D. Lee, "Optimizing parallelism of big data analytics at distributed computing system," International Journal on Advanced Science, Engineering and Information Technology, vol. 7, pp. 1716-1721, 2017.

Int J Pow Elec \& Dri Syst, Vol. 10, No. 1, March 2019 : $93-103$ 
[23] J. Oyelade, E. Uwoghiren, I. Isewon, O. Oladipupo, O. Aromolaran, and K. Michael, "Machine learning and sentiment analysis: Examining the contextual polarity of public sentiment on malaria disease in social networks," in 10th International Conference on Bioinformatics and Computational Biology,. pp. 210-218, 2018.

[24] T. A. Al-asadi, A. J. Obaid, R. Hidayat, and A. A. Ramli, "A survey on web mining: Techniques and applications," International Journal on Advanced Science, Engineering and Information Technology, vol. 7, pp. 1178-1184, 2017.

[25] A. H. Wahbeh, Q. A. Al-Radaideh, M. N. Al-Kabi, and E. M. Al-Shawakfa, "A comparison study between data mining tools over some classification methods," International Journal of Advanced Computer Science and Applications, vol. 8, pp. 18-26, 2011.

[26] S. Yu, D. Zhao, W. Chen, and H. Hou, "Oil-immersed power transformer internal fault diagnosis research based on probabilistic neural network," Procedia Computer Science, vol. 83, pp. 1327-1331, 2016.

[27] M. R. Berthold, N. Cebron, F. Dill, T. R. Gabriel, T. Kötter, T. Meinl, et al., "KNIME: The Konstanz Information Miner," in Data Analysis, Machine Learning and Applications, pp. 319-326, 2008.

[28] M. O. Okelola and O. Elijah, Detection of Voltage Unbalance on Three Phase Induction Motor Using Artificial Neural Network, International Journal of Emerging Trends in Engineering and Development, vol. 4, pp. 18-25, 2018.

[29] M. A. Jirdehi and A. Rezaei, "Parameters estimation of squirrel-cage induction motors using ANN and ANFIS," Alexandria Engineering Journal, vol. 55, pp. 357-368, 2016.

[30] S. Vijayan and S. Paramasivam, "Fault diagnosis and management system for switched reluctance motor drives," International Journal of Computer Applications in Technology, vol. 32, pp. 224-231, 2008.

[31] M. K. Saini and A. Aggarwal, "Detection and diagnosis of induction motor bearing faults using multiwavelet transform and naive Bayes classifier," International Transactions on Electrical Energy Systems, vol. 28, 2018.

[32] K. Mohanraj, S. Paramasivam, S. S. Dash, and A. F. Zobaa, "Open and short circuit diagnosis of a VSI fed three phase induction motor drive using fuzzy logic technique," International Review on Modelling and Simulations, vol. 6, pp. 1858-1864, 2013.

Determining the operational status of a three phase induction motor using ... (Aderibigbe Israel Adekitan) 